\title{
Preparation and Characterization of Paclitaxel-loaded PLGA Nanoparticles Coated with Cationic SM5-1 Single-chain Antibody
}

\author{
Geng Kou ${ }^{1,2, \#}$, Jie Gao ${ }^{1, \#}$, Hao Wang ${ }^{1,2}$, Huaiwen Chen ${ }^{1}$, Bohua Li $^{1,2}$, Dapeng Zhang ${ }^{1}$, Shuhui Wang ${ }^{1}$, \\ Sheng Hou ${ }^{1,2}$, Weizhu Qian ${ }^{1,2}$, Jianxin Dai ${ }^{1}$, Yanqiang Zhong' and Yajun Guo ${ }^{1,2, *}$ \\ ${ }^{1}$ International Joint Cancer Institute and College of Pharmacy, Second Military Medical University, \\ New Library Building West $10^{\text {th }}-11^{\text {th }}$ Floor, 800 Xiang Yin Road, Shanghai 200433, People's Republic of China \\ ${ }^{2}$ Shanghai Center for Cell Engineering and Antibody, 399 Libing Road, Shanghai 201203, People's Republic of China
}

Received 28 March 2007, Accepted 25 April 2007

\begin{abstract}
The purpose of this study was to develop paclitaxel-loaded poly(lactide-co-glycolide) (PLGA) nanoparticles coated with cationic SM5-1 single-chain antibody (scFv) containing a polylysine (SMFv-polylys). SM5-1 ScFv (SMFv) is derived from SM5-1 monoclonal antibody, which binds to a $230 \mathrm{kDa}$ membrane protein specifically expressed on melanoma, hepatocellular carcinoma and breast cancer cells. SMFv-polylys was expressed in Escherichia coli and purified by cation-exchange chromatography. Purified SMFv-polylys was fixed to paclitaxel-loaded PLGA nanoparticles to form paclitaxel-loaded PLGA nanoparticles coated with SMFv-polylys (Ptx-NP-S). Ptx-NP-S was shown to retain the specific antigen-binding affinity of SMFv-polylys to SM5-1 binding protein-positive Ch-hep-3 cells. Finally, the cytotoxicity of Ptx-NP-S was evaluated by a non-radioactive cell proliferation assay. It was demonstrated that Ptx-NP-S had significantly enhanced in vitro cytotoxicity against $\mathrm{Ch}$-hep-3 cells as compared with non-targeted paclitaxel-loaded PLGA nanoparticles. In conclusion, our results suggest that cationic SMFv-polylys has been successfully generated and may be used as targeted ligand for preparing cancer-targeted nanoparticles.
\end{abstract}

Keywords: Nanoparticles, Paclitaxel, PLGA, Single-chain antibody, SM5-1

\footnotetext{
${ }^{\#}$ These authors contribute equally to this paper

*To whom correspondence should be addressed. Tel: 86-21-25070241, Fax: 86-21-25074349

E-mail: yjguo@smmu.edu.cn
}

\section{Introduction}

Targeted nanoparticles, composed of copolymer nanoparticles and targeted ligands, could specifically target tumor cells whereas reduce considerably possible side-effects (Moshfeghi et al., 2005). The copolymer nanoparticles are made of copolymers and drugs such as chemotherapeutics which are encapsulated in or linked to the copolymer (Allen, 2002; Mo and Lim, 2005). Recently, the copolymer receiving the most attention is poly(lactide-co-glycolide) (PLGA) which has been approved by the Food and Drug Administration (FDA) for use in sutures and drug delivery devices for the controlled and/or targeted drug delivery (Panyam and Labhasetwar, 2003).

It is very important to couple targeted ligands to nanoparticles in making targeted nanoparticles (Nobs et al., 2004). The most common approach described for the design of targeted nanoparticles is adsorption of antibodies to their surface without affecting the activities of antibodies (Nichkova et al., 2006; Powell and Yoon, 2006). PLGA nanoparticles have surface ionizable groups (e.g., carboxyls) that are negatively charged at neutral buffer (Ataman-Onal et al., 2006; Kazzaz et al., 2006), and the protein affinity for the PLGA nanoparticle surface depends strongly on the isoelectric point (pI) and electrostatic forces (Powell and Yoon, 2006). In neutral $\mathrm{pH}$ 7.4 buffer, the cationic protein can be easily adsorbed to negatively charged PLGA nanoparticles (Chaska et al., 2005). Moreover, the cationic polypeptide polylysine (polylys) is commonly used in adsorption of cationic polymers to negatively charged DNA in gene transfer, and the electrostatic interaction is an important factor in the adsorption (Pashkovskaya et al., 2006; Lv et al., 2006). Therefore, we suppose that the protein containing a polylys can be easily adsorbed to negatively charged PLGA nanoparticles.

SM5-1 is a member of a panel of mouse monoclonal antibodies generated by using a subtractive immunization 
protocol as previously described (Trefzer et al., 2000). SM5-1 binds to a membrane protein of about $230 \mathrm{kDa}$ (SM5-1 binding protein), which is specifically expressed on melanoma, hepatocellular carcinoma and breast cancer cells, making it a promising candidate for cancer targeted therapy (Trefzer et al., 2000; Reinke et al., 2005; Trefzer et al., 2006). However, the administration of mouse $\mathrm{mAb}$ in humans for therapeutic purposes has been limited by their immunogenicity and poor tissue penetration in vivo (Xiong et al., 2005). One way to overcome the limitation is to genetically prepare a singlechain antibody $(\mathrm{scFv})$ derived from the mouse mAb (Carter, 2001).

In this article, we employed recombinant DNA techniques to fuse polylys to a scFv derived from SM5-1 mAb and the resulting fusion protein (SMFv-polylys) was produced by prokaryotic expression system, purified with cation-exchange chromatography, and characterized for its binding affinity to SM5-1 binding protein-positive Ch-hep-3 cells, which is a human hepatocellular carcinoma cell lines maintained in our lab (Zhao et al., 2001; Song et al., 2005; Wang et al., 2007). Then, we encapsulated paclitaxel (as a model drug), which is an extract of the bark of pacific yew tree and recognized as an effective anticancer drug against a wide spectrum of solid tumors (Mo and Lim, 2005), in PLGA nanoparticles using emulsion-solvent evaporation technique. After SMFv-polylys was fixed to paclitaxel-loaded PLGA nanoparticles to form paclitaxel-loaded PLGA nanoparticles coated with SMFvpolylys (Ptx-NP-S), the specific binding, cross-reactivity and internalization of Ptx-NP-S was evaluated by flow cytometry and confocal microscopy. Compared with non-targeted paclitaxel-loaded PLGA nanoparticles (Ptx-NP), Ptx-NP-S had significantly enhanced in vitro cytotoxicity against Chhep-3 cells.

\section{Materials and Methods}

Materials. Three human hepatocellular carcinoma cell lines (Chhep-1, Ch-hep-3 and QGY7701) and two human normal liver cell lines (L02 and Chang) were maintained in our lab. The two cell lines, Ch-hep-1 and Ch-hep-3, were generated by International Joint Cancer Institute, Second Military Medical University. The plasmid pGEMT-SMVH containing SM5-1 heavy chain variable region and pGEMT-SMVL containning SM5-1 light chain variable region were constructed and deposited in International Joint Cancer Institute, Second Military Medical University. The plasmid pET28a(+), Escherichia coli strains BL21(DE3) and DH5a were purchased from Merck Biosciences. SP Sephadex c-25 column was purchased from Amersham Pharmacia Biotech. PLGA (50:50, RG502, MW 14.5 kDa) was obtained from Boehringer Ingelheim Inc. Polyvinyl alcohol was obtained from Aldrich Chemical, Inc., Munich, Germany. Chloroform and paclitaxel were purchased from Sigma. All salts and buffers used in this study were of reagent grade. Organic solvents were of HPLC grade.
Plasmid construction of SMFv-polylys. The heavy and light chain variable regions of SM5-1 were amplified from pGEMTSMVH and pGEMT-SMVL by PCR, respectively. The heavy chain variable region gene of SM5-1 was fused to the 5' end of light chain variable region gene via a (Gly4Ser)3 linker sequence using the overlapping PCR method to generate SM5-1 single-chain antibody (SMFv) gene. The nucleotide sequences of $\mathrm{V}_{\mathrm{H}}$ and $\mathrm{V}_{\mathrm{L}}$ were determined and deposited in European Molecular Biology Laboratory (EMBL) database under the accession numbers DQ781317 and DQ781318, respectively. The following primers were used to make the SMFvpolylys with a N-terminal $6 \mathrm{His}$-tag and a C-terminal polylys: 5'ATcatatgGAGGTCCAGCTGCAGCAG-3' and 5'-ATctcgagTTACT TTTTCTTTTTCTTTTTCTTTTTCTTTTTAGAACCACCGCCT CCGG-3'. Lowercase letters represent restriction endonuclease recognition sites. The final PCR product was cloned into pGEM-T vector (Promega, Madison, WI) and its sequence was verified. Then the fusion gene was excised by NdeI and XhoI digestion and inserted into the $\mathrm{NdeI} / \mathrm{XhoI}$ site of the $\mathrm{pET}-28 \mathrm{a}(+)$ vector, yielding the expression vector pET-SMFv-polylys.

Expression and purification of SMFv-polylys. For the SMFvpolylys production in BL21(DE3), cells were grown in LB broth containing $50 \mu \mathrm{g} / \mathrm{ml}$ kanamycin and with shaking at $37^{\circ} \mathrm{C}$ until the OD $(600 \mathrm{~nm})$ was 0.8 . Then, $\mathrm{scFv}$ production was induced by the addition of $1 \mathrm{mM}$ isopropyl- $\beta$-D-thiogalactopyranoside (IPTG) (Treerattrakool et al., 2006). Four hours after induction, $50 \mathrm{ml}$ cultures were pelleted by centrifugation. The pelleted cells were thawed on ice, resuspended in $20 \mathrm{mM}$ Tris- $\mathrm{Cl}$ (pH 8.0), and lysed by sonication in ice-water bath. The lysate was clarified at $10,000 \times \mathrm{g}$ for $30 \mathrm{~min}$ at $4^{\circ} \mathrm{C}$ and both soluble fraction and pellet containing the insoluble fraction (inclusion bodies) were analyzed by SDS-PAGE. The supernatant was filtered $(0.45 \mu \mathrm{m}$ pores $)$ and ready for purification. $\mathrm{ScFv}$ purification from the crude cell extract was conducted on ÄKTA FPLC chromatographic system (Pharmacia, Sweden). Crude extract was applied onto a SP Sephadex c-25 column, which was preconditioned with $20 \mathrm{mM}$ sodium citrate, $\mathrm{pH}$ 7.0. The extract was first washed with $20 \mathrm{mM}$ sodium citrate, $\mathrm{pH} 7.0$, to remove unbound proteins and then eluted with programmed gradient of $0-100 \%$ of $20 \mathrm{mM}$ sodium citrate, $\mathrm{pH}$ 7.0, containing $500 \mathrm{mM} \mathrm{NaCl}$ (Fig. 3). The eluted fraction containing SMFv-polylys was dialyzed against phosphate-buffered saline (PBS, $\mathrm{pH}$ 7.4) and stored at $-20^{\circ} \mathrm{C}$. All fractions were collected and subjected to SDS-PAGE analysis.

SDS-PAGE and western blot. Samples were incubated at $100^{\circ} \mathrm{C}$ for $5 \mathrm{~min}$ in sample buffer $(0.25 \mathrm{M}$ Tris-Cl, $\mathrm{pH} 6.8,5 \%$ glycerol, $5 \%$ 2-mercaptoethanol, 3\% SDS, and $0.2 \mathrm{mg} / \mathrm{ml}$ bromphenolblue) and then separated by SDS-PAGE (10\% gels). For Western-blot, the proteins separated by electrophoresis were transferred to nitrocellulose membrane (Millipore) using a Mini TransBlot cell (Bio-Rad Inc.), blocked in 1\% BSA in TBS (100 mM Tris, 0.9\% $\mathrm{NaCl}, \mathrm{pH} 7.5)$ and immunoreacted with $1: 3000$ dilution of mouse anti-His monoclonal antibody (TIANGEN, China), followed by HRP-labelled goat anti-mouse IgG (Zymed Lab). Chromogenicbased detection was performed using 3,3'-diaminobenzidine (DAB) as a staining substrate. 
Development of nanoparticles. Paclitaxel-loaded or drug-free PLGA nanoparticles (Ptx-NP or NP) were prepared using an emulsion solvent evaporation technique as described before (Chavanpatil et al., 2006). Then, Ptx-NP coated with SMFv-polylys (Ptx-NP-S) was prepared as described previously (Ataman-Onal et al., 2006). Briefly, SMFv-polylys was diluted in $10 \mathrm{mM} \mathrm{pH} 5.7$ phosphate buffer at a concentration of $0.8 \mathrm{mg} / \mathrm{ml}$. Ptx-NP was diluted at a concentration of $10 \mathrm{mg} / \mathrm{ml}$ (PLGA copolymer concentration) in milliQ water and added to the above protein solution at a volume ratio of $1: 1$. The adsorption reaction was left to occur overnight at room temperature, with moderate stirring end over head. The Ptx-NP-S pellets were collected by centrifugation at $30,000 \times \mathrm{g}$ for $5 \mathrm{~min}$ and washed thrice with PBS. Meanwhile, drug-free PLGA nanoparticles coated with SMFv-polylys were prepared in the same way. To fabricate FITC-PLGA nanoparticles, fluorescein isothiocyanate (FITC) was conjugated to the terminal group of PLGA as previously described (Sun et al., 2005). The following designations are used: Ptx-NP (paclitaxel-loaded PLGA nanoparticles), Ptx-NP-S (paclitaxel-loaded PLGA nanoparticles coated with SMFv-polylys), FITC-Ptx-NP-S (FITC labeled PtxNP-S), and FITC-Ptx-NP (FITC labeled Ptx-NP). Drug-free PLGA nanoparticles with and without conjugation with SMFv-polylys, are designated as NP-S and NP, respectively.

Characterization of nanoparticles. The mean size, size distribution and zeta potential of the nanoparticles were determined using a particle size analyzer (Zeta Sizer 3000HS, Malvern Instruments). Surface morphology and size were also determined by JEOL 2010 Transmission Electronic Microscopy (TEM, accelerating voltage of $200 \mathrm{kV}$ ). Paclitaxel content in the PLGA nanoparticles for calculation of dosing quantity was determined on HPLC system consisting of a C-18 column $(4.6 \mathrm{~mm} \times 25 \mathrm{~cm})$ with $5 \mu \mathrm{m}$ packing (Beckmann Instruments, Fullerton, CA) by using a UV detector at $228 \mathrm{~nm}$. The SMFv-polylys adsorption efficiency, which was calculated as the weight of protein (microgram SMFv-polylys) associated with unit weight (milligram) of lyophilized nanoparticles, was determined by MicroBCA protein assay kit (Pierce) as described by Sah (Sah, 1997).

Competitive binding assays. Ch-hep- 3 cells at $1 \times 10^{6}$ cells $/ \mathrm{ml}$ were incubated with sub-saturated concentration of FITC labeled SM5-1 mAb (FITC-SM5-1) and increasing concentrations of antibodies or nanoparticles for $1 \mathrm{~h}$ at $4^{\circ} \mathrm{C}$. The cells were then washed and analyzed by Flow cytometry analysis (FCM). FCM was performed using a FACScan flow cytometer (Becton Dickinson). The $\mathrm{IC}_{50}$ values of competitors were calculated using a four parameter algorithm.

Cross-reactivity of Ptx-NP-S among normal cell lines. To examine the cross-reactivity of Ptx-NP-S among normal cell lines, two human normal liver cell lines including L02 and Chang were tested by FCM. Ch-hep-3 cells were used as a positive control. Briefly, $1 \times 10^{5}$ cells were incubated with $2 \mathrm{mg} / \mathrm{ml}$ FITC labeled nanoparticles (saturated PLGA concentration) for $1 \mathrm{~h}$ at $4^{\circ} \mathrm{C}$. The cells were then washed and analyzed by FCM.

Laser-scannning confocal microsopy. Binding and internalization of FITC labeled nanoparticles in SM5-1 binding protein-positive cell lines including Ch-hep-1 and Ch-hep-3 were examined by laser-scanning confocal microscopy. Cells were incubated with the nanoparticles for $10 \mathrm{~min}$ or $2 \mathrm{~h}$ at $37^{\circ} \mathrm{C}$. Then the cells were washed twice followed by fixation with $4 \% p$-formaldehyde (PFA) for 30 $\min$ at $4^{\circ} \mathrm{C}$. Afterwards, DAPI (Invitrogen) was used to counterstain the nuclei of the cells. Finally, cells were imaged by Leica TCS SP2 Confocal Spectral Microscope (UV-VIS).

In vitro cytotoxicity assays. Ch-hep-3 or QGY7701 cells were grown in 96-well plates at $1 \times 10^{4}$ cells/well for $24 \mathrm{~h}$. The cells were then incubated with serially diluted nanoparticles for another 24 h. Cell viability was determined by Cell Titer 96 non-radioactive cell proliferation assay kit (Promega, Madison) according the manufacturer's protocol. Briefly, the excess samples were removed by washing, followed by addition of $20 \mu \mathrm{l}$ MTS [3-(4,5-dimethylthiazol-2-yl)-5-(3-carboxymethoxyphenyl)-2-(4-sulfophenyl)-2Htetrazolium, inner salt $] /$ phenazine methosulfate solution. After incubation for $2 \mathrm{~h}$ at $37^{\circ} \mathrm{C}$, the absorbance was measured at $490 \mathrm{~nm}$ using BIO-TEK ELx800 Universal Microplate Reader. Cytotoxicity of NP-S and NP without paclitaxel was evaluated at $24 \mathrm{~h}$ at the highest concentration used in the cytotoxicity assays. Values are expressed as mean $\pm \mathrm{SD}$. For comparison between the two experimental groups, Student's $t$ test was used.

\section{Results}

Construction and expression of SMFv-polylys. The recombinant plasmid SMFv-polylys was constructed in a pET28a-(+) prokaryotic expression system (Fig. 1) and transformed into BL21(DE3). As shown in Fig. 2, SDS-PAGE revealed that a protein of a predicted band of $31 \mathrm{kDa}$ was strongly expressed. Further, the expression was linearly increased during the initial $4 \mathrm{~h}$ induction and then decreased. Analysis of the soluble and insoluble fractions of the induced $E$. coli cells extract indicated that the protein was expressed as both soluble fraction and inclusion bodies.

Purification of SMFv-polylys. Since the scFv is a 6Histagged protein, we tried nickel-immobilized metal affinity chromatography to get purified SMFv-polylys but got unsatisfactory results (data not shown). Because the calculated SMFv-polylys $\mathrm{pI}$ is 9.3, we performed a cation-exchange chromatography at $\mathrm{pH}$ 7.0. $20 \mathrm{mM}$ sodium citrate, $\mathrm{pH}$ 7.0, was used as the initial column conditions for loading the crude SMFv-polylys extract on SP Sephadex c-25 column. The crude extract was then washed with $20 \mathrm{mM}$ sodium citrate, $\mathrm{pH} 7.0$, until the absorbance at $280 \mathrm{~nm}$ returned to baseline, which indicated removal of unbound protein and other impurities (Fig. 3). SMFv-polylys was then eluted by slowing increasing the ionic strength of the buffer by introducing a linear gradient of $20 \mathrm{mM}$ sodium citrate, $\mathrm{pH} 7.0,0-500 \mathrm{mM}$ $\mathrm{NaCl}$. A final column wash with four column volumes of $1 \mathrm{M}$ $\mathrm{NaOH}$ removed unwanted cell extract materials. The fractions were collected and analyzed by SDS-PAGE analysis (Fig. 4). Densitometry scanning of the SDS-PAGE gel showed that the purity of SMFv-polylys was $95 \%$. To insure the expressed and 


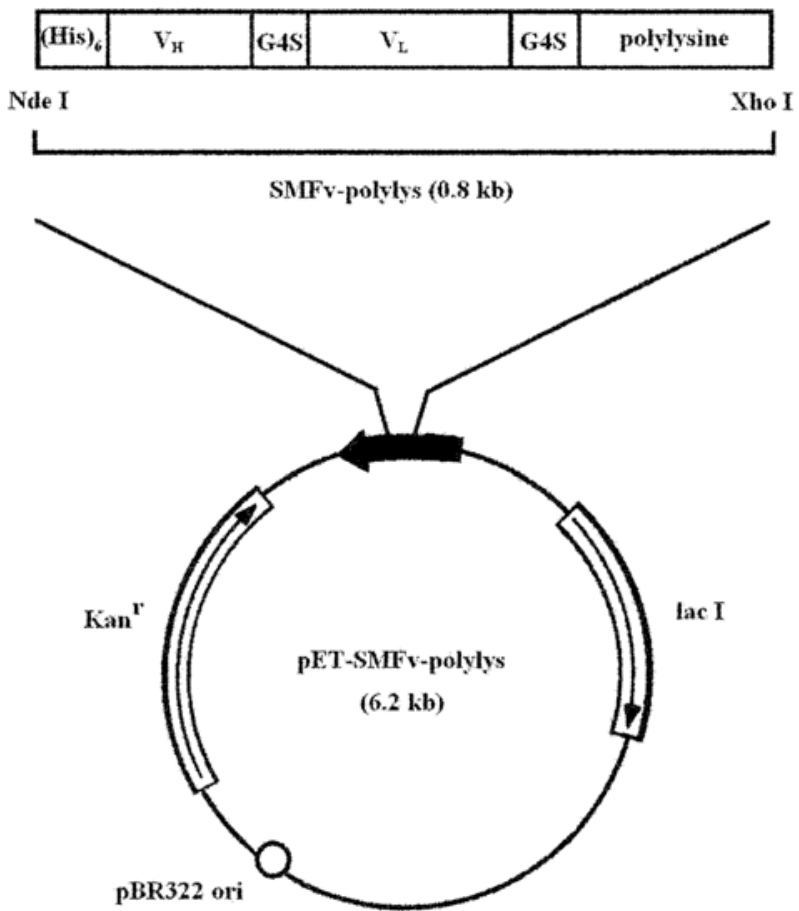

Fig. 1. Construction of the expression vector pET-SMFv-polylys. $\mathrm{V}_{\mathrm{H}}$, the variable region gene of heavy chain of SM5-1 mAb; $\mathrm{V}_{\mathrm{L}}$, the variable region gene of light chain of SM5-1 mAb; (His) denote a sequence encoding six N-terminal histidine residues; G4S, a sequence encoding (Gly4Ser)3 linker; polylysine, a sequence encoding polylyine; $\mathrm{Kan}^{\mathrm{r}}$, the kanamycin resistance gene; ori, origin of DNA replication; lac I, lac regulator gene encoding lac repressor.

purified recombinant protein was the SMFv-polylys we had designed, the sample after induction and purified protein were subjected to Western-blot. The recombinant protein showed high immunoreactivity with anti-His antibody (Fig. 4). The results confirmed the successful expression and purification of SMFv-polylys. Meanwhile, the control antibody CD11c scFv containing a polylys (CD11cFv-polylys) was also successfully constructed, expressed and purified (data not shown).

Development of nanoparticles and stability of Ptx-NP-S. We used an emulsion solvent evaporation technique to encapsulate paclitaxel within PLGA and developed Ptx-NP. The drug loading efficiency of Ptx-NP was 70.1 $\pm 5.2 \mu \mathrm{g}$ drug/mg NP (mean $\pm \mathrm{SD} ; \mathrm{n}=3)$. The Ptx-NP had a mean diameter of $119 \pm 6.2 \mathrm{~nm}($ mean $\pm \mathrm{SD} ; \mathrm{n}=10)$ and a zeta potential of $-31.5 \pm 1.2 \mathrm{mV}$ (mean $\pm \mathrm{SD} ; \mathrm{n}=3$ ). After the adsorption of SMFv-polylys on Ptx-NP, Ptx-NP-S had a mean diameter of $129 \pm 5.2 \mathrm{~nm}$ (mean $\pm \mathrm{SD} ; \mathrm{n}=10$ ), presumably attributed to the presence of SMFv-polylys on the nanoparticles' surfaces. The surface morphology and size distribution of PtxNP-S were evaluated by TEM (Fig. 5). Also, Ptx-NP-S had a zeta potential of $-4.6 \pm 0.3 \mathrm{mV}$ (mean $\pm \mathrm{SD} ; \mathrm{n}=3$ ), indicating that SMFv-polylys adsorption induced a considerable decrease,

\section{$\begin{array}{llllllll}1 & 2 & 3 & 4 & 5 & 6 & M & \text { kDa }\end{array}$}

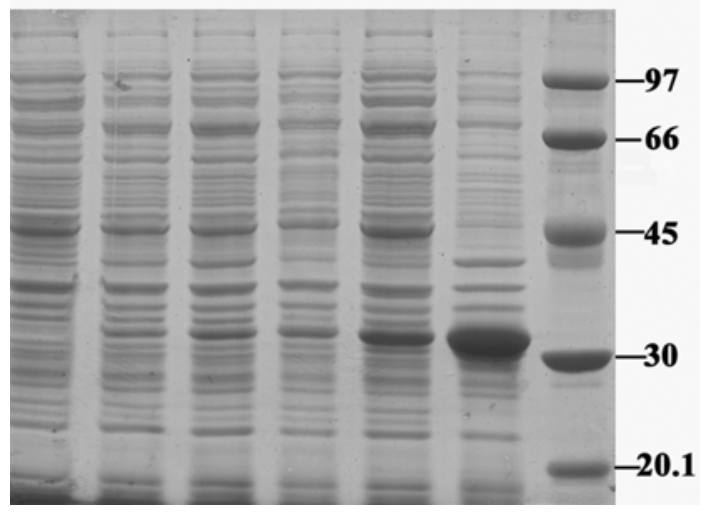

Fig. 2. Expression of the recombinant protein SMFv-polylys. Protein sample were prepared as follows: The whole cell lysate before induction (lane 1) and after 2, 4 or $6 \mathrm{~h}$ induction (lanes 24 respectively). Lane 5 , soluble fraction after cell sonication; lane 6 , inclusion bodies after cell sonication; lane $\mathrm{M}$, low molecular weight marker (Amersham Biosciences).

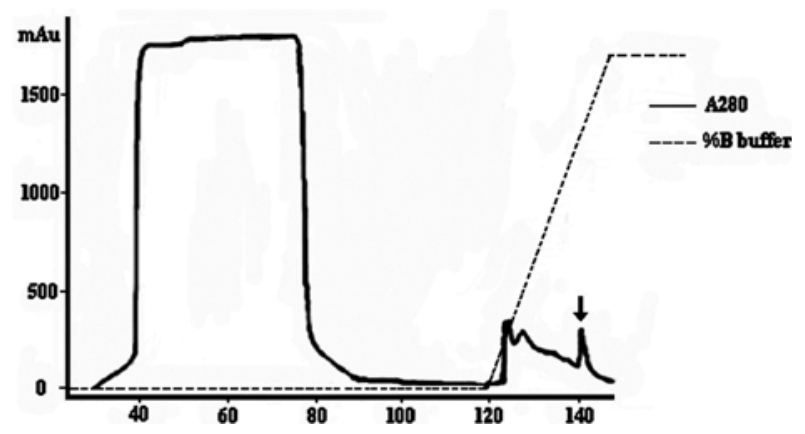

Fig. 3. Chromatogram of the crude cell extract on a SP Sephadex c-25 column. The column was preconditioned and washed with buffer A ( $20 \mathrm{mM}$ sodium citrate, $\mathrm{pH} 7.0)$. The bound protein was eluted by a programmed gradient of $0-100 \%$ buffer B of $20 \mathrm{mM}$ sodium citrate, $\mathrm{pH} 7.0$, containing $500 \mathrm{mM}$ $\mathrm{NaCl}$. SM5-1-polylys (arrow) was eluted as the third eluting peak. The flow rate was $1 \mathrm{ml} / \mathrm{min}$.

in absolute value, of zeta potential with regard to Ptx-NP $(-31.5 \pm 1.2 \mathrm{mV})$. According to the MicroBCA assays, the adsorption efficiency was obtained as $20.3 \pm 1.5 \mu \mathrm{g}$ (mean \pm $\mathrm{SD} ; \mathrm{n}=3$ ) SMFv-polylys/mg nanoparticles. The stability of Ptx-NP-S was analyzed as previously described (10). Briefly, Ptx-NP-S (400 $\mu \mathrm{M}$ in PBS, paclitaxel concentration), which was the formulation tested in cytotoxicity assays, was kept at $4^{\circ} \mathrm{C}$ for several days. No significant variation in particle size was observed until day 30. However, the mean diameter reached $240 \mathrm{~nm}$ by day 60 , most probably due to nanoparticle aggregation. During this time period, we also monitored the release of SMFv-polylys from Ptx-NP-S at $4^{\circ} \mathrm{C}$, no release was observed at day 30, whereas small amounts of unbound SMFv-polylys could be detected at day 60 . we can safely conclude that Ptx-NP-S are stable for about 30 days at $4^{\circ} \mathrm{C}$. 
(A)

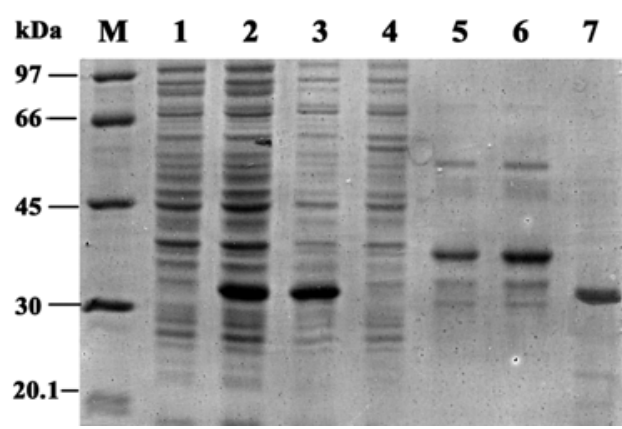

(B)

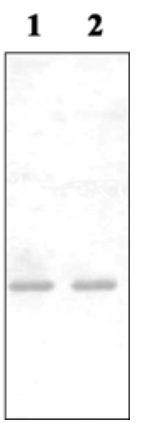

Fig. 4. SDS-PAGE and Western-blot analysis of purification of SMFv-polylys by cation-exchange chromatography. (A) Lane 1, the whole cell lysate before induction; lane 2, the whole cell lysate after induction; lane 3, soluble fraction after cell sonication; lane 4, flow through; lane 5, first peak elution from the column using buffer B containing $500 \mathrm{mM} \mathrm{NaCl}$; lane 6 , second peak elution from the column using buffer B; lane 7 , target protein SMFv-polylys with a purity of $95 \%$ eluted as the third peak; lane $\mathrm{M}$, low molecular weight marker (Amersham Biosciences). (B) The expression and purification of SMFvpolylys were confirmed by Western-blot. Lane 1, the whole cell lysate after induction; lane 2, target protein SMFv-polylys with a purity of $95 \%$ eluted as the third peak.

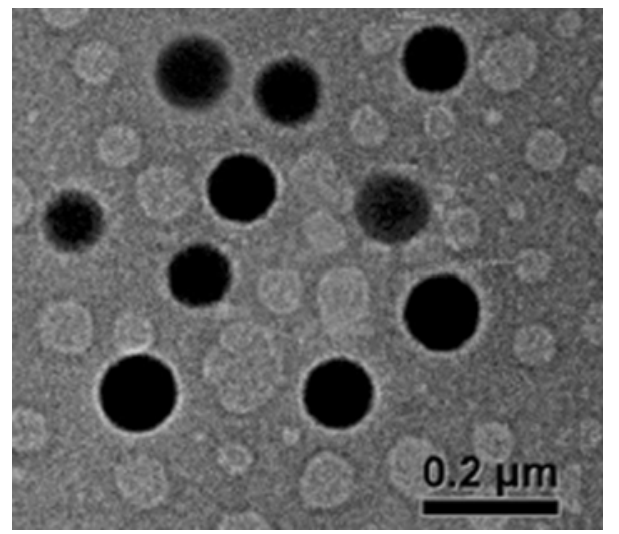

Fig. 5. Representative transmission electronic microscopy image of Ptx-S-P. Ptx-NP-S has a mean diameter of $129 \pm 5.2 \mathrm{~nm}$ (mean $\pm \mathrm{SD} ; \mathrm{n}=10$ ).

Similarly, we also evaluated the stability of Ptx-NP-S under other different conditions such as $\mathrm{pH}$, ionic strength, and temparature (Table 2).

Competitive binding assays. As shown in Fig. 6, both SMFv-polylys and Ptx-NP-S could compete with SM5-1 for binding to Ch-hep-3 cells, suggesting both of them retained the specific antigen-binding affinity. The avidity of Ptx-NP-S was higher than that of SMFv-polylys $\left[\mathrm{IC}_{50}\right.$ of $13.66 \pm 3.97$ $\mu \mathrm{g} / \mathrm{ml}$ vs. $23.45 \pm 4.35 \mu \mathrm{g} / \mathrm{ml}$ for Ptx-NP-S vs. SMFv-polylys, respectively (mean $\mathrm{IC}_{50} \pm \mathrm{SD} ; \mathrm{n}=3$ ); $P<0.05$ ], indicating the adsorption of SMFv-polylys to PLGA nanoparticles did not
Table 1. The cytotoxic activity of nanoparticles on two hepatocellular carcinoma cell lines

\begin{tabular}{ccc}
\hline \multirow{2}{*}{ Nanoparticles } & \multicolumn{2}{c}{$\mathrm{IC}_{50}(\mu \mathrm{M})^{a}$} \\
\cline { 2 - 3 } & Ch-hep-3 & QGY7701 \\
\hline Ptx-NP-S & $21.7 \pm 5.1$ & $91.2 \pm 6.7$ \\
Ptx-NP & $69.6 \pm 2.2$ & $89.7 \pm 8.9$ \\
NP-S & ND & ND \\
NP & ND & ND \\
\hline
\end{tabular}

${ }^{a}$ Data are expressed as mean $\pm \mathrm{SD}(\mathrm{n}=6) . \mathrm{ND}$, not done.

Table 2. The stability of Ptx-NP-S under different conditions

\begin{tabular}{cccc}
\hline $\mathrm{pH}$ & Buffer $(10 \mathrm{mM})$ & Temparature & $\begin{array}{c}\text { Time of } \\
\text { stability }(\text { day })^{a}\end{array}$ \\
\hline \multirow{2}{*}{5.0} & Citrate & $4^{\circ} \mathrm{C}$ & 40 \\
& & $37^{\circ} \mathrm{C}$ & 8 \\
7.4 & Phosphate (PBS) & $4^{\circ} \mathrm{C}$ & 30 \\
& & $37^{\circ} \mathrm{C}$ & 5 \\
9.0 & Borate & $4^{\circ} \mathrm{C}$ & 9 \\
& & $37^{\circ} \mathrm{C}$ & 2 \\
5.0 & Citrate $+50 \mathrm{mM} \mathrm{NaCl}$ & $4^{\circ} \mathrm{C}$ & 28 \\
& & $37^{\circ} \mathrm{C}$ & 5 \\
5.0 & Citrate $+250 \mathrm{mM} \mathrm{NaCl}$ & $4^{\circ} \mathrm{C}$ & 18 \\
\multirow{2}{*}{5.0} & Citrate $+800 \mathrm{mM} \mathrm{NaCl}$ & $4^{\circ} \mathrm{C}$ & 3 \\
& & $37^{\circ} \mathrm{C}$ & 10 \\
\hline
\end{tabular}

${ }^{a}$ All data were expressed as the mean of triplicate experiments.

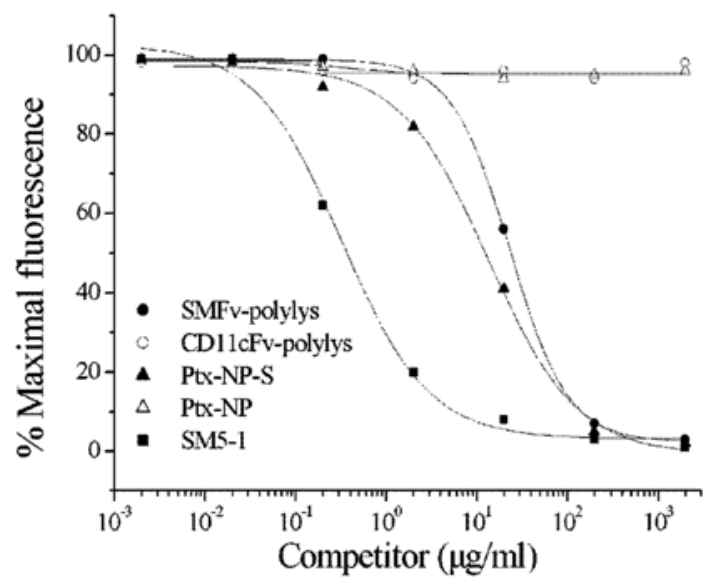

Fig. 6. Competitive binding assays. Ch-hep- 3 cells at $1 \times 10^{6}$ cells/ $\mathrm{ml}$ were incubated with sub-saturated concentration of FITC-SM51 and increasing concentrations of SMFv-polylys, CD11cFvpolylys, Ptx-NP-S ,Ptx-NP or SM5- 1 for $1 \mathrm{~h}$ at $4^{\circ} \mathrm{C}$. The cells were then washed and analyzed by FCM. Maximal fluorescence is defined as the mean channel fluorescence by staining Ch-hep-3 cells with FITC-SM5-1 in the absence of competitors. All data were expressed as the mean of triplicate samples.

alter its binding affinity and multivalency of binding of PtxNP-S improved its avidity. As expected, SM5-1 had a higher 
(A)

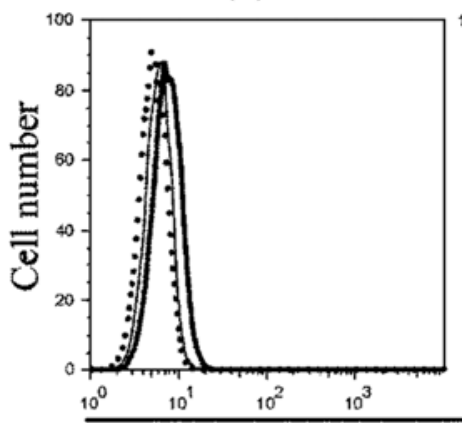

(B)

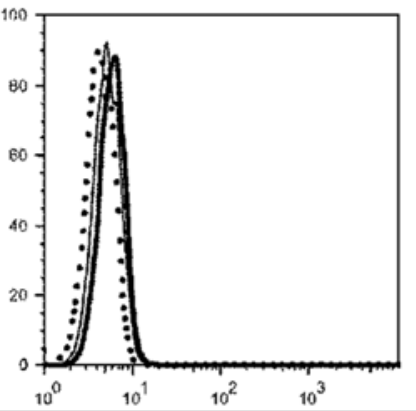

(C)

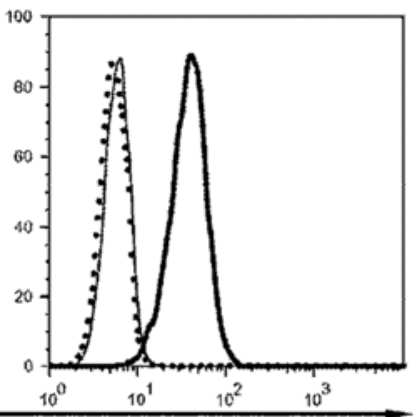

Fluorescence intensity

Fig. 7. Cross-reactivity assays. Cells were incubated with $2 \mathrm{mg} / \mathrm{ml}$ FITC-Ptx-NP-S (bold line) and FITC-Ptx-NP (thin solid line) for $1 \mathrm{~h}$ at $4^{\circ} \mathrm{C}$ and were analyzed by FCM. In additon, cells treated with FITC labeled goat anti-mouse IgG (Zymed) (broken line) were used as a negative control. (A) L02; (B) Chang; (C) Ch-hep-3.

Ptx-NP-S
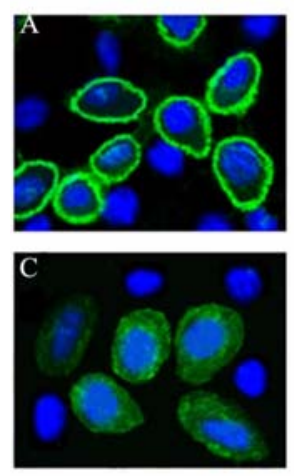

Ptx-NP
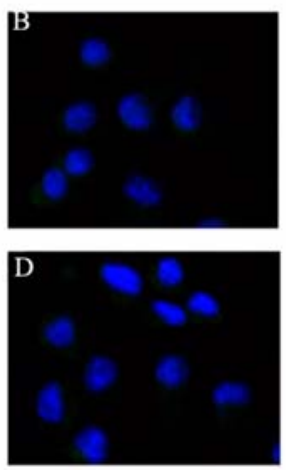

$10 \mathrm{~min}$

2 h

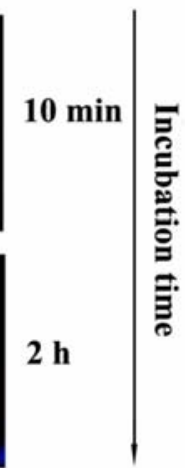

Fig. 8. The time course of the binding and internalization of FITC-Ptx-NP-S (A, C), FITC-Ptx-NP (B, D) in Ch-hep-3 cells. Ch-hep-3 cells were stained according to the following conditions: (A, B) $10 \mathrm{~min}$; (C, D) $2 \mathrm{~h}$. Green fluorescene of FITC and blue fluorescene of DAPI were analyzed.

avidity $\left[0.32 \pm 0.04 \mu \mathrm{g} / \mathrm{ml}\left(\right.\right.$ mean $\left.\left.\mathrm{IC}_{50} \pm \mathrm{SD}\right) ; \mathrm{n}=3\right]$ than PtxNP-S and SMFv-polylys.

Cross-reactivity assays. Ptx-NP-S was evaluated for its cross-reactivity with the normal human cells. As shown in Fig. 7, Ptx-NP-S did not cross react with L02 and Chang cells. However, in Ch-hep-3 cells, Ptx-NP-S possessed a specific antigen-binding affinity.

Laser-scannning confocal microsopy. To confirm the internalization effiency of Ptx-NP-S, Ch-hep-3 cells incubated with FITC labeled nanoparticles were analyzed by laser scanning confocal microscopy. As shown in Fig. 8, in Ch-hep3 cells, Ptx-NP-S was mainly localized on the cellular membrane after a 10-minute incubation. Significant internalization was observed in Ch-hep-3 cells after a 2-hour incubation. Membrane localization and internalization were not found in Ch-hep-3 cells incubated with non-targeted Ptx-NP. In Ch- hep-1 cells, similar results were obtained (data not shown).

In vitro cytotoxicity assays. Cytotoxicity of the Ptx-NP-S and Ptx-NP were evaluated in the paclitaxel concentration of 1 to $400 \mu \mathrm{M}$ (equivalent to PLGA concentration of up to $4.87 \mathrm{mg} /$ ml). As shown in Table 1, against Ch-hep-3 cells, Ptx-NP-S was significantly more cytotoxic as compared with control Ptx-NP lacking SMFv-polylys [ $\mathrm{IC}_{50}$ of $21.7 \pm 5.1 \mu \mathrm{M}$ vs. 69.6 $\pm 2.2 \mu \mathrm{M}$ for Ptx-NP-S vs. Ptx-NP, respectively (mean $\pm \mathrm{SD}$ ); $P<0.001$ ] (Table 1). In contrast, Ptx-NP-S and Ptx-NP had very similar cytotoxicity against SM5-1 binding proteinnegative QGY7701 cells $\left[\mathrm{IC}_{50}\right.$ of $91.2 \pm 6.7 \mu \mathrm{M}$ vs. $89.7 \pm 8.9$ $\mu \mathrm{M}$ for Ptx-NP-S vs. Ptx-NP, respectively (mean $\pm \mathrm{SD}$ ); $P>0.05]$. Further, the $\mathrm{IC}_{50}$ value for Ptx-NP-S was 4.2-fold lower for the Ch-hep-3 cells than for the QGY7701 cells. All results indicated Ptx-NP-S had specific cytotoxicity against SM5-1 binding protein-positive Ch-hep-3 cell line. Meanwhile, cytotoxicity of NP-S and NP without paclitaxel was evaluated at the PLGA concentration of $4.87 \mathrm{mg} / \mathrm{ml}$ (data not shown). The results confirmed that, in the absence of paclitaxel, NP-S and NP showed negligible cytotoxicity to Ch-hep-3 and QGY7701 cells.

\section{Discussion}

The use of targeted nanoparticles as drug delivery vehicles for anticancer therapeutics has great potential to revolutionize the future of cancer therapy. These targeted nanoparticles can selectively target cancer sites and carry large payloads, thereby improving cancer detection and therapeutic effectiveness (Mitra, 2006). Several chemotherapeutics-encapsulated targeted PLGA nanoparticles proved their potential utility for cancer therapeutic application (Mo and Lim, 2005; Farokhzad et al., 2006). In producing targeted nanoparticles, coupling targeted ligands to nanoparticles is critical (Nobs, et al., 2004). Covalent reactions appear to be an effective way to fix ligands, such as monoclonal antibodies or peptides, to nanoparticles, but it has 
to be kept in mind that the covalent reaction must not affect the biological activity of ligands (Nobs, et al., 2004). In the case of PLGA nanoparticles, carbodiimide chemistry is a commonly used method that coupling antibodies to PLGA nanoparticles (Mo and Lim, 2005; Farokhzad et al., 2006). The covalent reactions require the need of chemical reagents that can potentially interfere with subsequent reactions or damage the targeted ligands and/or the nanoparticles (Nobs, et al., 2004).The most common approach described for the design of targeted nanoparticles is adsorption of antibodies to their surface without affecting the activities of antibodies (Nichkova et al., 2006; Powell and Yoon, 2006).

PLGA nanoparticles made with poly(lactide-co-glycolide) copolymer are negatively charged at neutral buffer. Various proteins with a wide range of $\mathrm{pI}$ were adsorbed to PLGA nanoparticles with different adsorption efficiency (Chaska et al., 2005). Electrostatic interaction is a significant driving force for protein adsorption to PLGA nanoparticles, and the protein with a higher isoelectric point has higher adsorption efficiency than the protein with a lower isoelectric point under the same condition (Chaska et al., 2005). In our study, we used a novel, efficient and rapid method by electrostatic interactions to couple cationic SMFv-polylys with a calculated pI of 9.3 to negatively charged PLGA nanoparticles, with an adsorption efficiency of $20.3 \pm 1.5 \mu \mathrm{g}$ SMFv-polylys/mg nanoparticles. Also, Ptx-NP-S had a zeta potential of $-4.6 \pm$ $0.3 \mathrm{mV}$ (mean $\pm \mathrm{SD} ; \mathrm{n}=3$ ), indicating that cationic SMFvpolylys adsorption induced a considerable decrease, in absolute value, of zeta potential with regard to Ptx-NP $(-31.5$ $\pm 1.2 \mathrm{mV}$ ). Additionally, compared with the same amount of PLGA microparticles (mean diameter $>1 \mu \mathrm{m}$ ), our Ptx-NP -S (mean diameter $=129 \mathrm{~nm}$ ) had higher protein adsorption efficiency (data not shown), since the protein adsorption capacity scales with the available surface area (i.e. protein adsorption sites) (Chaska et al., 2005).

The choice of the targeted ligands is also a critical factor in targeted nanoparticles design. To efficiently deliver encapsulated chemotherapeutics to targeted tumor cells, the targeted ligands must be able to bind to the cell surface, internalize and deliver the chemotherapeutics to the cell cytosol. In the cytosol, the released chemotherapeutics exhibit their cytotoxic effects. Our previous study showed that SM5-1 had a high specificity and affinity for SM5-1 binding protein expressed on malignant cell lines (Trefzer, et al., 2000; Reinke, et al., 2007). Also, SM5-1 could be effectively internalized after rapidly and specifically binding to SM-1 binding protein-positive cells, suggesting that SM5-1 was a promising candidate for targeted nanoparticles construction (Wang et al., 2007). After successfully produced by a bacterial system, soluble SMFv-polylys was obtained with a high purity by a single-step cation-exchange chromatography, avoiding the refolding of the inclusion bodies of SMFv-polylys. The inclusion bodies often resulted in the accumulation of misfolded and incorrect conformation of the $\mathrm{scFv}$, hence decreasing the affinity of the antibodies towards their antigens (Su et al., 2003). Since much of the soluble form of protein is active, soluble scFv expression is very attractive (Caetano et al., 2006; Chayaratanasin et al., 2007). Competitive assays indicated that SMFv-polylys retained specific binding affinity to SM5-1 binding proteinpositive cells, suggesting SMFv-polylys was a promising candidate for targeted nanoparticles construction. Therefore, we tentatively put forward that introducing a polylysine to a $\mathrm{scFv}$ may faciliate its purification through cation-exchage chromatography without affecting its binding affinity.

Paclitaxel, an extract of the bark of pacific yew tree, is recognized as an effective anticancer drug against a wide spectrum of solid tumors (Mo and Lim, 2005). The intracellular action together with the dose- and exposure time-dependent anti-angiogenic and anti-metastatic activities of paclitaxel make it a good candidate for localized delivery (Mo and Lim, 2005). Since paclitaxel-loaded PLGA nanoparticles have been developed by several groups with varying degrees of success (Fonseca et al., 2002), we encapsulated paclitaxel (as a model drug) within PLGA nanoparticles. First, we generated paclitaxelloaded PLGA nanoparticles coated with SMFv-polylys (PtxNP-S) that was shown to retain specific binding affinity to SM5-1 binding protein without cross-reactivity to several normal human cells (Fig. 7). In the competitive binding assays, we found the avidity of Ptx-NP-S was higher than that of SMFv-polylys, suggesting the adsorption of SMFv-polylys to PLGA nanoparticles did not alter its binding affinity and multivalency of binding of Ptx-NP-S improved its avidity. Afterwards, by confocal microscopic analysis, it was shown that Ptx-NP-S not only bound to the outer surface of SM5-1 binding protein-positive cells but was also internalized. Finally, cytotoxicity assays demonstrated that the ranking order of sensitivity towards Ptx-NP-S was Ch-hep-3 > QGY7701 cells, the $\mathrm{IC}_{50}$ value for Ptx-NP-S being 4.2-fold lower for the Ch-hep-3 cells than for the QGY7701 cells. PtxNP-S was significantly more cytotoxic against Ch-hep-3 cells as compared with control Ptx-NP. In constrast, against SM5-1 binding protein-negative QGY7701 cells, Ptx-NP-s and PtxNP had very similar cytotoxicity. In conclusion, we believed that Ptx-NP-S could specifically kill SM5-1 binding proteinpositive hepatocellular carcinoma cells by binding to SM5-1 binding protein. We suppose that the high anti-proliferation activity of Ptx-NP-S was achieved by at least two mechanisms. The surface-SMFv-polylys could initiate receptor-mediated endocytosis by binding to SM5-1 binding protein in the cell membrane. Once inside the cytoplasm or nucleus, the loaded paclitaxel was released to arrest cell growth (Mo and Lim, 2005). Additionally, we tested the stability of Ptx-NP-S under different conditions. As shown in Table 2, Ptx-NP-S became considerablely instable as the $\mathrm{pH}$, temparature, and salt concentration increased, indicating electrostatic interaction is a significant driving force for SMFv-polylys adsorption to PLGA nanoparticles and the effect of salt concentration or temparature on adsorption is very strong. In $10 \mathrm{mM}$ phosphate buffer (PBS, pH 7.4), Ptx-NP-S was stable during a 40-day period at $4^{\circ} \mathrm{C}$, without aggregation and release of SMFv- 
polylys. In Ptx-NP-S in PBS kept at $4^{\circ} \mathrm{C}$ for 40 days, the binding affinity and cytotoxic activity were very similar to the results obtained with freshly prepared Ptx-NP-S (data not shown). Based on these results, it seems that Ptx-NP-S developed in this work may be considered promising systems for in vivo paclitaxel delivery. Additionally, the administration of $\mathrm{scFv}$ derived from mouse $\mathrm{mAb}$ in humans for therapeutic purposes still has been limited by their immunogenicity, so scFv derived from fully human antibody might be better choice. Recently, we have successfully constructed a highaffinity humanized SM5-1 mAb (Li et al., 2007). In the subsequent research, we will construct Ptx-NP-S whose SMFv-polylys is derived from humanized SM5-1 mAb.

In summary, we have successfully generated a novel cationic SMFv-polylys and it was efficiently fixed to the paclitaxelloaded PLGA nanoparticles. Then we demonstrated that PtxNP-S retained the specific binding affinity to SM5-1 binding protein and could induced specific and efficient death of Chhep-3 cells, suggesting SMFv-polylys may be used as targeted ligand for preparing cancer-targeted PLGA nanoparticles. Although the focus of the current studies has been on paclitaxel targeting, the strategy should also apply to other nanoparticles encapsulated therapeutics, such as other chemotherapeutics and protein. Additional studies are under investigation to further characterize Ptx-NP-S including in vivo stability, biodistribution, antitumor efficacy and the mechanisms by which tumor inhibition is induced.

Acknowledgments This work was supported by grants from National Natural Science Foundation of China, Shanghai Commission of Science \& Technology, Ministry of Science and Technology of China (973\&863 program projects), Shanghai Pudong commission of Science \& Technology and a special grant from E-institute of Shanghai Universities Immunology Division. We thank Ms. Yang Yang and Ms. Jing $\mathrm{Xu}$ for their technical assistance.

\section{References}

Allen, T. M. (2002) Ligand-targeted therapeutics in anticancer therapy. Nat. Rev. Cancer 2, 750-763.

Ataman-Onal, Y., Munier, S., Ganee, A., Terrat, C., Durand, P. Y., Battail, N., Martinon, F., Le, G. R., Charles, M. H., Delair, T. and Verrier, B. (2006) Surfactant-free anionic PLA nanoparticles coated with HIV-1 p24 protein induced enhanced cellular and humeral immune responses in various animal models. J. Control. Release 112, 175-185.

Caetano, B., Drobecq, H. and Soncin, F. (2006) Expression and purification of recombinant vascular endothelial-statin. Protein Expr. Purif. 46, 136-142.

Carter, P. (2001) Improving the efficacy of antibody-based cancer therapies. Nat. Rev. Cancer 1, 118-129.

Chaska, J., Kazak, J., Uqozzoli, M., O'hagan, D. T. and Singh, M. (2005) An investigation of the factors controlling the adsorption of protein antigens to anionic PLG microparticles. $J$.
Pham. Sci. 94, 2510-2519.

Chavanpatil, M. D., Patil, Y. and Panyam, J. (2006) Susceptibility of nanoparticle-encapsulated paclitaxel to P-glycoproteinmediated drug efflux. Int. J. Pharm. 320, 150-156.

Chayaratanasin, P., Moonsom, S., Sakdee, S., Chaisri U., Katzenmeier, G. and Angsuthanasombat, C. (2007) High level of soluble expression in Escherichia coli and characterisation of the cloned Bacillus thuringiensis cry4ba domain III fragment. J. Biochem. Mol. Biol. 40, 58-64.

Farokhzad, O. C., Cheng, J., Teply, B. A., Sherifi, I., Jon, S., Kantoff, P. W., Richie, J. P. and Langer, R. (2006) Targeted anoparticle-aptamer bioconjugates for cancer chemotherapy in vivo. Proc. Natl. Acad. Sci. USA 103, 6315-6320.

Fonseca, C., Simoes, S. and Gaspar, R. (2002) Paclitaxel-loaded PLGA nanoparticles: preparation, physicochemical characterization and in vitro anti-tumoral activity. J. Control. Release 83, 273286.

Kazzaz, J., Singh, M., Ugozzoli, M., Chesko, J., Soenawan, E. and O'hagan, D. T. (2006) Encapsulation of the immune potentiators MPL and RC529 in PLG microparticles enhances their potency. J. Control. Release 110, 566-573.

Li, B., Wang, H., Zhang, D., Qian, W., Hou, S., Shi, S., Zhao, L., Kou, G., Cao, Z., Dai, J. and Guo, Y. (2007) Construction and characterization of a high-affinity humanized SM5-1 monoclonal antibody. Biochem. Biophys. Res. Commun. 357, 951-956.

Lv, H., Zhang, S., Wang, B., Cui, S. and Yan, J. (2006) Toxicity of cationic lipids and cationic polymers in gene delivery. $J$. Control. Release 114, 100-109.

Mitra, A., Nan, A., Line, B. R. and Ghandehari, H. (2006) Nanocarriers for nuclear imaging and radiotherapy of cancer. Curr. Pharm. Des. 12, 4729-4749.

Moshfeghi, A. A. and Peyman, G. A. (2005) Micro- and nanoparticulates. Adv. Drug Deli. Rev. 57, 2047-2052.

Mo, Y. and Lim, L. Y. (2005) Preparation and in vitro anticancer activity of wheat germ agglutinin (WGA)-conjugated PLGA nanoparticles loaded with paclitaxel and isopropyl myristate. $J$. Control. Release 107, 30-42.

Nichkova, M., Dosev, D., Perron, R., Gee, S. J., Hammock, B. D. and Kennedy, I. M. (2006) $\mathrm{Eu}^{3+}$-doped $\mathrm{Gd} 2 \mathrm{O} 3$ nanoparticles as reporters for optical detection and visualization of antibodies patterned by microcontact printing. Anal. Bioanal. Chem. 384, 631-637.

Nobs, L., Buchegger, F., Gurny, R. and Allemann, E. (2004) Current methods for attaching targeting ligands to liposomes and nanoparticles. J. Pham. Sci. 93, 1980-1992.

Panyam, J. and Labhasetwar, V. (2003) Biodegradable nanoparticles for drug and gene delivery to cells and tissue. Adv. Drug Del. Rev. 55, 329-347.

Pashkovskaya, A. A., Lukashev, E. P., Antonov, P. E., Finogenova, O. A., Ermakov, Y. A., Melik-Nubarov, N. S. and Antonenko, Y. N. (2006) Grafting of polylysine with polyethylenoxide prevents demixing of O-pyromellitylgramicidin in lipid membranes. Biochim. Biophys. Acta 1758, 1685-1695.

Powell, T. and Yoon, J. Y. (2006) Fluorescent biorecognition of gold nanoparticle-IgG conjugates self-assembled on E-beam patterns. Biotechnol. Prog. 22, 106-110.

Reinke, S., Koniger, P., Herberth, G., Audring, H., Wang, H., Ma, J., Guo, Y., Sterry, W. and Trefzer, U. (2005) Differential expression of MART-1, tyrosinase, and SM5-1 in primary and metastasis melanoma. Am. J. Dermatopathol. 27, 401-406. 
Sah, H. (1997) A new strategy to determine the actual protein content of poly(lactide-co-glycolide) microspheres. J. Pharm. Sci. 86, 1315-1318.

Song, S. C., Xue, J. Y., Fan, K. X., Kou, G., Zhou, Q., Wang, H. and Guo, Y. J. (2005) Preparation and characterization of fusion protein truncated Pseudomonas Exotoxin A (PE38KDEL) in Escherichia coli. Protein Expr. Purif. 44, 52-57.

Sun, H. K., Ji, H. J., Ki, W. C. and Tae, G. P. (2005) Targetspecific cellular uptake of PLGA nanoparticles coated with poly(L-lysine)-poly(ethylene glycol)-folate conjugate. Langmuir 21, 8852-8857.

Su, Y. C., Lim, K. P. and Nathan, S. (2003) Bacterial expression of the scFv fragment of a recombinant antibody specific for Burkholderia pseudomallei exotoxin. J. Biochem. Mol. Biol. 36, 493-498.

Treerattrakool, S., Udomkit, A. and Panyim, S. (2006) Anti-CHH antibody causes impaired hyperglycemia in Penaeus monodon. J. Biochem. Mol. Biol. 39, 371-376.

Trefzer, U., Chen, Y., Herberth, G., Hofmann, M. A., Kiecker, F., Guo, Y. and Sterry, W. (2006) The monoclonal antibody SM5-
1 recognizes a fibronectin variant which is widely expressed in melanoma. BMC. Cancer 11, 6-8.

Trefzer, U., Rietz, N., Chen, Y., Audring, H., Herberth, G., Siegel, P., Reinke, S., Koniger, P., Wu, S., Ma, J., Liu, Y., Wang, H., Sterry, W. and Guo, Y. (2000) SM5-1: a new monoclonal antibody which is highly sensitive and specific for melanocytic lesions. Arch. Der. Res. 292, 583-589.

Wang, H., Song, S., Kou, G., Li, B., Zhang, D., Hou, S., Qian, W., Dai, J., Tian, L., Zhao, J. and Guo, Y. (2007) Treatment of hepatocellular carcinoma in a mouse xenograft model with an immunotoxin which is engineered to eliminate vascular leak syndrome. Cancer Immunol. Immunother. doi:10.1007/s00262007-0321-4.

Xiong, H., Ran, Y., Xing, J., Yang, X., Li, Y. and Chen, Z. (2005) Expression vectors for human-mouse chimeric antibodies. $J$. Biochem. Mol. Biol. 38, 414-419.

Zhao, J., Wang, H., Wei, L., Habib, N. A., Lu, X., Wu, M. and Guo, Y. (2001) The cytotoxic effect of E1B 55-kDa mutant adenovirus on human hepatocellular carcinoma cell lines. Cancer Gene. Ther. 8, 333-341. 